\title{
Critical assessment of DTA-DSC methods for the study of nucleation kinetics in glasses
}

\author{
Vladimir M. Fokin ${ }^{\mathrm{a}, *}$, Aluísio A. Cabral ${ }^{\mathrm{b}}$, Raphael M.C.V. Reis ${ }^{\mathrm{c}}$, Marcio L.F. Nascimento ${ }^{\mathrm{c}}$, Edgar D. Zanotto ${ }^{\mathrm{c}}$ \\ a S.I. Vavilov's State Optical Institute, 36-1 Babushkina, 193171 St. Petersburg, Russia \\ ${ }^{\mathrm{b}}$ Department of Physics - DEFIS, Federal Institute of Maranhao - IFMA, Brazil \\ ${ }^{\mathrm{c}}$ Vitreous Materials Laboratory - LaMaV, DEMa, Federal University of São Carlos, Brazil
}

\section{A R T I C L E I N F O}

\section{Article history:}

Received 24 March 2009

Available online 29 December 2009

\section{Keywords:}

Crystallization

Crystal growth

Glass ceramics

Nucleation

Alkali silicates

\begin{abstract}
A B S T R A C T
Microscopy methods are usually employed to estimate the number density of super critical nuclei and the resulting crystal nucleation rates, $I(T)$. These traditional techniques rely on a double-stage treatment, i.e. the development of the nuclei at a temperature higher than the previous nucleation temperature up to a size large enough to be visible with optical or electron microscopy. These methods can give reliable results for $I(T)$, but are rather laborious and time-consuming. On the other hand, non-isothermal (DTA/ DSC) methods are, in principle, much faster. In this paper, we experimentally test two non-isothermal methods by comparison with a traditional optical microscopy method. We found that, if they are properly employed, non-isothermal methods can give useful kinetic information, which includes the crystal number density and nucleation rates, but to get accurate quantitative data they need some preliminary information about nucleation and growth rates in the studied glass and, in addition, are as laborious as the traditional microscopy methods!
\end{abstract}

(ㄷ) 2009 Elsevier B.V. All rights reserved.

\section{Introduction}

Crystal nucleation and growth rates and the related induction periods for nucleation determine glass crystallization kinetics. The knowledge of nucleation rates and their temperature dependence in glass forming melts are not only of great scientific importance, e.g. to understand glass formation, but are also of practical interest for the development and industrial production of glassceramics.

To estimate the number density of super critical nuclei, Tammann's method [1] has been commonly employed in the last 40 years. This method consists in the development of such nuclei at a relatively high temperature (higher than a previous nucleation temperature) up to a size large enough to be visible with optical or electron microscopy. The method allows one to determine crystal nucleation rates covering a wide range of values. For instance, for various silicate glasses, the measured crystal nucleation rates vary from $10 \mathrm{~m}^{-3} \mathrm{~s}^{-1}$ to $10^{13} \mathrm{~m}^{-3} \mathrm{~s}^{-1}$ [2]. Despite the fact that it gives correct values of nucleation rate and time-lag for nucleation, Tammann's method is quite laborious and has limitations [2]. Beginning in 1980s, alternative methods based on DTA/DSC experiments have been proposed, see e.g. [3-8] to study crystallization

E-mail address: vfokin@pisem.net (V.M. Fokin).

URL: http://www.lamav.ufscar.br (V.M. Fokin). kinetics in glasses. As opposed to Tammann's method, these nonisothermal methods deal with the overall crystallization kinetics (combined nucleation and growth) and can be divided in two groups:

(I) The first type allows one to determine only the temperature dependence of the nucleation rates. In this analysis, the temperature range where nucleation can occur including the temperature where the nucleation rate is a maximum can be known, but not the quantitative values of the nucleation rates. Such types of non-isothermal methods are based on the reasonable assumption that the inverse temperature of the crystallization peak, $1 / T_{c}$, on a DSC/DTA curve is proportional to the number density of nuclei [4], since the higher the crystal number the faster is the overall crystallization kinetics and, hence, the release of the heat of crystallization can be detected at a lower temperature. Therefore, a plot of $1 / T_{\mathrm{c}}$ versus $T_{\mathrm{N}}$, the temperature of nucleation treatment for a given time, may reflect the temperature dependence of the nucleation rate, or more exactly, of the crystal number density nucleated in a given period of time. Sometimes, the height of the crystallization peak is also used [5,6], since, to a first approximation, the peak area is considered constant, while its width is determined by the time for complete crystallization, which depends on the number of nuclei and on the crystal growth rate. Thus one can expect a decrease of 
the peak width and, hence, an increase of its height with increasing number nuclei. However, this assumption is correct only at constant crystal growth rate, i.e. when the crystallization peak position does not depend on the number of nuclei. Weinberg [9] and Kelton [10] independently showed that the peak height method proposed by Ray and Day [11] is valid under certain conditions. These authors also showed that the $1 / T_{\mathrm{c}}$ method can more accurately predict the temperature dependence of the nucleation rates than the peak height method.

(II) The second type, proposed by Ray et al. [7] for quantitative determination of the steady-state nucleation rates as a function of temperature is based on a previous heat treatment of the glass samples to induce partial crystallization and on the estimation of the crystallized volume fraction via the decrease of the crystallization peak area, $A$, of the residual glass on a DTA/DSC curve. The preliminary nucleation at $T_{\mathrm{N}}$ for time $t_{\mathrm{N}}$ plus growth at $T_{\mathrm{G}}>T_{\mathrm{N}}$ for time $t_{\mathrm{G}}$ lead to a decrease of the fraction of residual glassy matrix. The crystallized volume fraction, $\alpha$, is given by the JMAYK (Johnson-Mehl-Avrami-Yerofeeyev-Kolmogorov [12-15]) equation, Eq. (1), adjusted for growth of a given number of crystals with constant rate $U$ :

$$
\alpha\left(t_{\mathrm{G}}\right)=1-\exp \left(-\frac{4 \pi}{3}\left(I\left(T_{\mathrm{N}}\right) t_{\mathrm{N}}+N_{\mathrm{at}}\right) U\left(T_{\mathrm{G}}\right)^{3} t_{\mathrm{G}}^{3}\right) .
$$

Here $\left(I\left(T_{\mathrm{N}}\right) t_{\mathrm{N}}+N_{\mathrm{at}}\right)$ is the total number of nuclei formed by nucleation at $T_{\mathrm{N}}$ with rate $I$ plus athermic nuclei $\left(N_{\mathrm{at}}\right)$, which include the nuclei formed during cooling of the melt (quenched-in nuclei, $N_{\mathrm{q}}$ ) and during the heating run up to the temperature $T_{\mathrm{G}}$.

The decrease of the residual glass fraction due to the preliminary crystallization reduces the DSC crystallization peak area, $A$, since, in the general case, $A$ is proportional to the mass of transformed material. By varying the growth time, $t_{\mathrm{G}}$, at fixed nucleation conditions $\left(T_{\mathrm{N}}\right.$ and $\left.t_{\mathrm{N}}\right)$ one can change $\alpha$ and $A$. The following equation was proposed by Ray et al. [7] for the ratio of peak areas corresponding to different $t_{\mathrm{G}}$.

$\frac{A_{1}}{A_{2}}=\frac{M_{1}\left[1-\frac{4 \pi}{3}\left(I t_{\mathrm{N}}+N_{\mathrm{at}}\right)\left(U t_{\mathrm{G} 1}\right)^{3}\right]}{M_{2}\left[1-\frac{4 \pi}{3}\left(I t_{\mathrm{N}}+N_{\mathrm{at}}\right)\left(U t_{\mathrm{G} 2}\right)^{3}\right]}$,

where $M_{1}$ and $M_{2}$ are the sample mass for two DSC runs corresponding to the time of preliminary growth, $t_{\mathrm{G} 1}$ and $t_{\mathrm{G} 2}$, respectively.

To derive Eq. (2) the exponential term in Eq. (1) was expanded. Hence Eq. (2) is limited to $\alpha<0.2$. By knowing $A_{i}, M_{i}$, $(i=1$ and 2$)$ and $U\left(T_{\mathrm{G}}\right)$, one can estimate $N_{\mathrm{at}}$ together with the number of crystals $N=I t_{\mathrm{N}}$ nucleated at $T_{\mathrm{N}}$ via Eq. (2). The number of athermic crystals can be estimated separately by the same equation, with the difference that the preliminary crystallization step does not include the nucleation procedure, i.e. $t_{\mathrm{N}}=0$.

Tests of the above described methods have been performed in Refs. $[7,8]$ using literature data for the nucleation and growth kinetics in stoichiometric lithium disilicate, $\mathrm{Li}_{2} \mathrm{O} \cdot 2 \mathrm{SiO}_{2}\left(\mathrm{~L}_{1} \mathrm{~S}_{2}\right)$ and sodium calcium silicate, $\mathrm{Na}_{2} \mathrm{O} \cdot 2 \mathrm{CaO} \cdot 3 \mathrm{SiO}_{2}\left(\mathrm{~N}_{1} \mathrm{C}_{2} \mathrm{~S}_{3}\right)$ glasses, which undergo internal nucleation. The method was also justified theoretically by comparing the nucleation rates from model calculations and computer generated DTA data [16]. However, the overall crystallization kinetics is very sensitive to the crystal growth rate $\left(U^{3}\right)$, which strongly depends on the glass viscosity, and can be significantly affected by departures of the nominal stoichiometry and impurities that are often not controlled, e.g. 'water'. Moreover, to correctly employ the value of growth rate one has to know the shape of the crystals, since in the common case of nonspherical shape, crystal growth cannot be characterized by a unique value.
The aim of the present paper is to experimentally test the main assumptions underlying the above described DSC/DTA methods by using our own data for glass samples produced from the same melts for both thermal analyses and optical measurements of crystallization kinetics. We give special attention to the ratio between surface and volume crystallization, and to the presence of 'quenched-in' nuclei, since the knowledge of their number is relevant for the estimation of the number density of crystals nucleated at given temperature. Finally, we perform a comparison between the nucleation rates measured by Tammann's method and by the DSC method. We do not carry out an extensive analysis, but merely show that the use of DSC/DTA for the study of crystallization kinetics demands utmost care and can be as laborious as the microscopy methods for quantitative determination of crystal number density and nucleation rates!

\section{Materials and methods}

Following Refs. [7,8], two silicate glasses with stoichiometric compositions $\mathrm{Li}_{2} \mathrm{O} \cdot 2 \mathrm{SiO}_{2}\left(\mathrm{~L}_{1} \mathrm{~S}_{2}\right)$ and $\mathrm{Na}_{2} \mathrm{O} \cdot 2 \mathrm{CaO} \cdot 3 \mathrm{SiO}_{2} \quad\left(\mathrm{~N}_{1} \mathrm{C}_{2} \mathrm{~S}_{3}\right)$ were employed as 'model' glasses. The glasses were synthesized in platinum crucibles in an electrical furnace at $1450-1500{ }^{\circ} \mathrm{C}$ for $2 \mathrm{~h}$. The chemicals used were sodium, lithium, and calcium carbonates of analytical grade (Synth and Mallinckrodt) and ground Brazilian quartz from Vitrovita $\left(>99.99 \% \mathrm{SiO}_{2}\right)$. The chemical analysis of the sodium calcium silicate glass is shown in Table 1 . The temperature of the DSC crystallization peak of the parent $\mathrm{L}_{1} \mathrm{~S}_{2}$ glass, which is sensitive to small departures of stoichiometry [17], and the experimental values of the nucleation and growth rates give indirect evidence that its composition is close to stoichiometric lithium disilicate. Thermal analyses were performed in a Netzsch 404 Differential Scanning Calorimeter (DSC) using monolithic pieces of about $35-38 \mathrm{mg}$. For the measurement of nucleation rate in $\mathrm{L}_{1} \mathrm{~S}_{2}$, the glass samples of about $41 \mathrm{mg}$ had regular shapes with sizes $2.9 \times 2.9 \times 2.1 \mathrm{~mm}$. The Tammann method [1,2] was employed to directly measure the crystal nucleation rates. The crystal sizes, numbers, and respective volume fractions in heat treated glass samples were estimated by a Leica DMRX optical microscope coupled with a Leica DFC490 CCD camera.

\section{Number of crystal nuclei and crystallization peak temperature}

To create different numbers of supercritical nuclei, the glass samples were heat treated for different periods of time at temperatures of appreciable nucleation rate (above glass transition temperature $T_{\mathrm{g}}$ ). Then each sample was divided into two parts: one part was subjected to a DSC run at a heating rate of $10^{\circ} \mathrm{C} / \mathrm{min}$, and the other was heat treated at a higher temperature to develop the nucleated crystals up to visible sizes in an optical microscope and to estimate its number density by stereological methods. Figs. 1 and 2 show the number of crystals versus nucleation time at $T=473{ }^{\circ} \mathrm{C}$ and $590{ }^{\circ} \mathrm{C}$ for $\mathrm{L}_{1} \mathrm{~S}_{2}$ and $\mathrm{N}_{1} \mathrm{C}_{2} \mathrm{~S}_{3}$ glasses, respectively. The solid lines resulted from fitting the experimental values $N(t)$ to the Colins-Kashchiev equation [18].

$N(t)=I_{\text {st }} \tau\left[\frac{t}{\tau}-\frac{\pi^{2}}{6}-2 \sum_{m}^{\infty} \frac{(-1)^{m}}{m^{2}} \exp \left(-m^{2} \frac{t}{\tau}\right)\right]$,

Table 1

Composition of $\mathrm{N}_{1} \mathrm{C}_{2} \mathrm{~S}_{3}$ glass by chemical analysis.

\begin{tabular}{llll}
\hline & $\mathrm{Na}_{2} \mathrm{O}(\mathrm{mol} \%)$ & $\mathrm{CaO}(\mathrm{mol} \%)$ & $\mathrm{SiO}_{2}(\mathrm{~mol} \%)$ \\
\hline Nominal & 16.67 & 33.33 & 50 \\
$\mathrm{~N}_{1} \mathrm{C}_{2} \mathrm{~S}_{3}$ glass & 17.2 & 32.3 & 50.5 \\
\hline
\end{tabular}




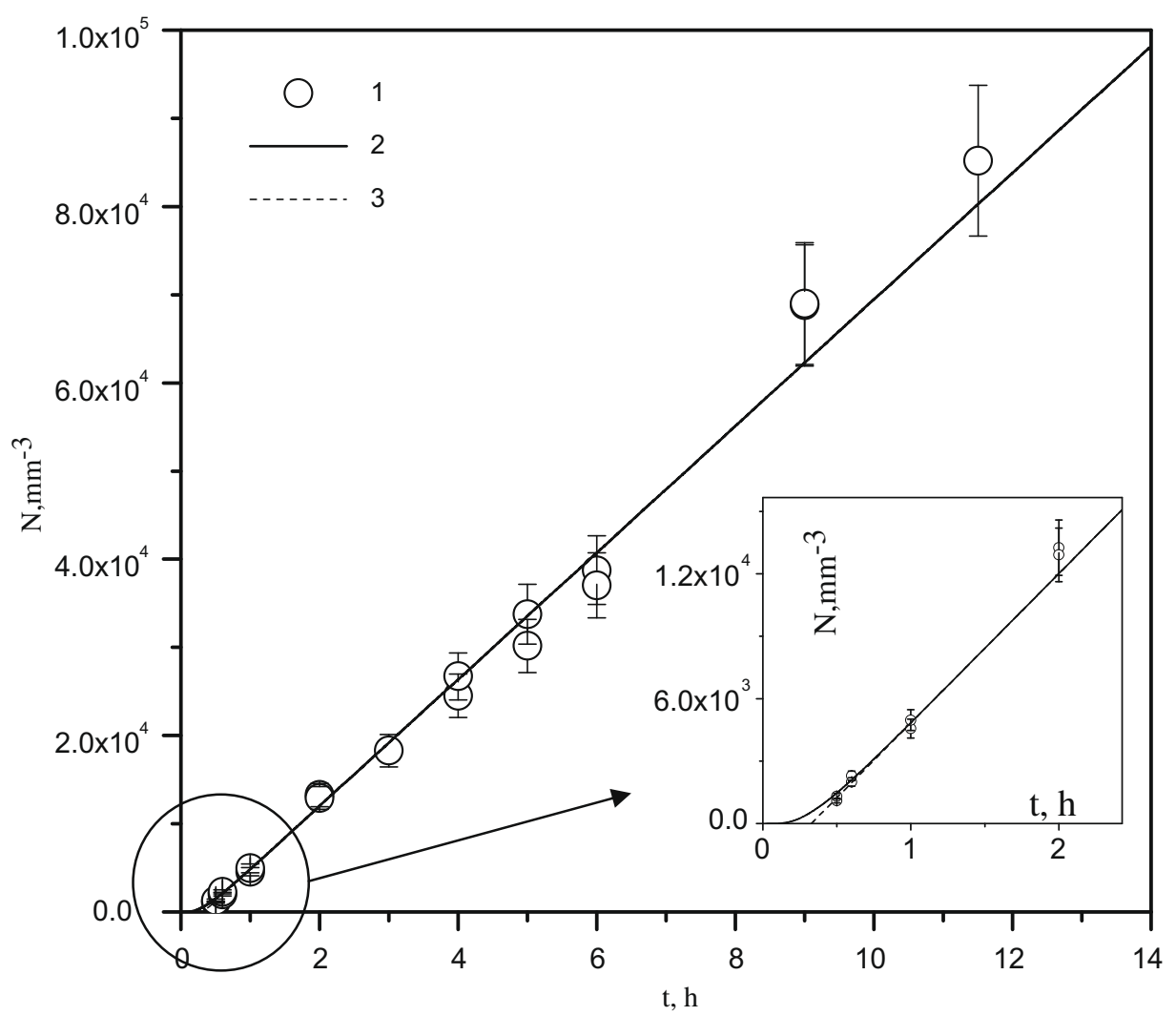

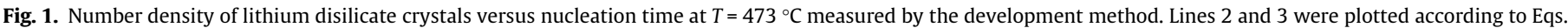
(3) and (4), respectively.

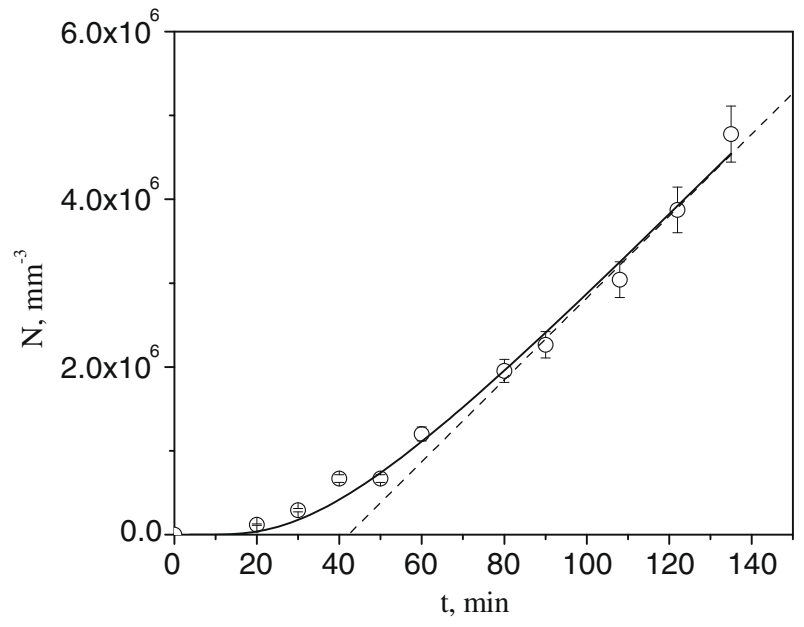

Fig. 2. Number density of crystals in $\mathrm{N}_{1} \mathrm{C}_{2} \mathrm{~S}_{3}$ glass versus time of nucleation at $T=590{ }^{\circ} \mathrm{C}$ measured by the development method. The solid and dotted lines were plotted by using Eqs. (3) and (4), respectively.

where $\tau$ is the time-lag for nucleation, which characterizes the time to achieve a steady-state nucleation rate $I_{\mathrm{st}}$.

The doted lines in these figures are the asymptote of Eq. (3) given by

$N(t)=I_{\mathrm{st}}\left(t-\frac{\pi^{2}}{6} \tau\right)$

Fig. 3 shows the dependencies of $1 / T_{\mathrm{c}}$ and $1 / T_{x}$ on the number of crystal nuclei previously nucleated in glass $\mathrm{L}_{1} \mathrm{~S}_{2}$ at $T=473{ }^{\circ} \mathrm{C} . T_{x}$ and $T_{\mathrm{c}}$ are, respectively, the temperatures of onset and maximum

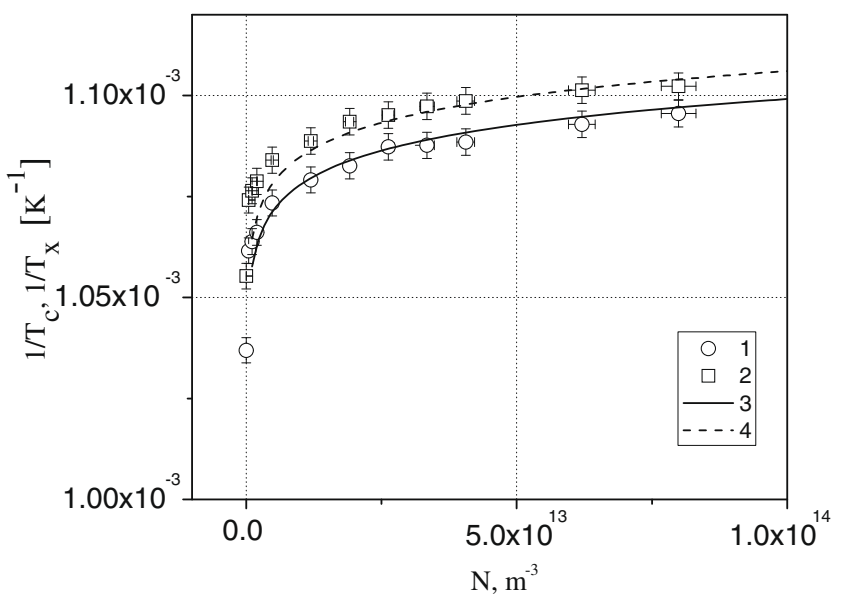

Fig. 3. $1 / T_{\mathrm{c}}(1)$ and $1 / T_{\mathrm{x}}(2)$ versus $N$ for lithium disilicate glass. The lines were fitted to Eq. (9), see text.

of the crystallization peaks (the volume fraction of crystals after typical nucleation treatments is vanishingly small and can be neglected). As we expected this dependency is not linear, and is close to logarithmic. These non-linear dependencies of $T_{\mathrm{c}}$, peak height and half-width on the nucleation time at $T=453^{\circ} \mathrm{C}$ were already also shown in Ref. [6] for similar lithium disilicate glass. However, the nucleation induction time at this temperature (about $3 \mathrm{~h}$ ) has the same magnitude as the total nucleation time $(10 \mathrm{~h})$ used in Ref. [6]. The fact that the number of nucleated crystals do not increase linearly with nucleation time complicates their analysis.

The following rough model can describe the experimental data shown in Fig. 3. We suppose that at the moment when the heat of 
crystallization is detected by a DSC or DTA the volume fraction crystallized achieved a certain value $\alpha$. To estimate the crystallized volume fraction we employ the JMAYK equation (Eq. (5)) neglecting crystal growth at temperatures lower than $T_{x}$. We also neglect the athermic crystals since, as will be shown later, for present glasses and experimental conditions their number is very low as compared with $N$.

$\alpha=1-\exp \left(-\frac{4 \pi}{3} \mathrm{NU}^{3} t^{3}\right)$.

We thus believe that this volume fraction $\alpha$ was crystallized via growth with rate $U(T)$ in a narrow temperature interval characterized by some effective temperature close to $T_{X}$ of the crystals preliminary nucleated at $T_{\mathrm{N}}\left[N=I\left(T_{\mathrm{N}}\right) t_{\mathrm{N}}\right]$. Since, in the temperatures of interest, the morphology of the lithium disilicate crystals is close to an ellipsoid of revolution, with growth rates along the minor and major diameters $U_{\min }$ and $U_{\max }$, respectively, the growth rate in Eq. (5) must be replaced by:

$U^{3}=U_{\min }^{2} U_{\max }=\frac{U_{\max }^{3}}{K^{2}}, K=\frac{U_{\max }}{U_{\min }}$,

where $K=U_{\max } / U_{\min }$. Then Eq. (5) can be rewritten as

$\ln \left(U_{\max }\right)=\frac{1}{3} \ln \left[-\frac{3 K^{2}}{4 \pi} \frac{\ln (1-\alpha)}{\mathrm{Nt}^{3}}\right]$.

Fig. 4 shows, as an example, the values of the maximum and minimum diameters of lithium disilicate crystals versus heat treatment time at $T=600^{\circ} \mathrm{C}$. The inset shows literature data on the temperature dependence of $U_{\max }$ for lithium disilicate glass [19] in Arrhenius coordinates. The stars corresponding to $T=600$ and $620^{\circ} \mathrm{C}$ (our own data for the present glass) are very close to the other points. At high temperatures $U_{\max }(T)$ can be approximated by the following equation (see solid line in Fig. 4, inset).

$\ln \left(U_{\max }, \mathrm{m} / \mathrm{s}\right)=23.79-36124.02 \frac{1}{T}, \quad \operatorname{Tin} K$.
Combining Eqs.(7) and (8), one obtains.

$$
\frac{1}{T}=\frac{23.79-\frac{1}{3} \ln \left[-\frac{3 K^{2}}{4 \pi} \frac{\ln (1-\alpha)}{\mathrm{Nt}^{3}}\right]}{36124.02} \text {. }
$$

Thus, Eq. (9) allows one to evaluate the inverse effective temperature (at which a given volume fraction, $\alpha$, crystallizes during a period of time $t$ ) as a function of the number of crystals, $N$. Curves 3 and 4 on Fig. 3 were plotted using Eq. (9) for $t=90 \mathrm{~s}$ and $\alpha=0.2$ and 0.1 , respectively. At heating rate $C=10^{\circ} \mathrm{C} / \mathrm{min}, t=90 \mathrm{~s}$ corresponds to a temperature interval of $15^{\circ} \mathrm{C}$. Despite the rough approximations, this model with reasonable parameters gives a semi-quantitative description of the experimental data. It should be noted that the model does not take surface crystallization into account (that is most important for low values of $N$ ). Maybe this would be the reason why at low values of $N$ the experimental points are above the calculated curves (see Fig. 3). A similar logarithmic dependence of $1 / T_{c}$ for the $N_{1} C_{2} S_{3}$ glass on $N$ is shown in Fig. 5.

The following comments on the method employing the shift of the crystallization peak to estimate a nucleation rate curve should be done:

i. This method gives an accurate temperature dependence of the nucleation rate only if non-steady-state nucleation can be neglected, i.e. the equality $N\left(T_{\mathrm{N}}\right)=I_{\mathrm{st}}\left(T_{\mathrm{N}}\right) t_{\mathrm{N}}$ holds, where $I_{\mathrm{st}}$ is the steady-state nucleation rate. This is the case of relative high temperatures (well above the glass transition temperature, $T_{\mathrm{g}}$ ) or long heat treatment time $t_{\mathrm{N}}$ that significantly exceeds the time-lag for nucleation at all studied temperatures. In all other cases the method will distort the temperature dependence of the nucleation rate at low temperatures (especially close to or below $T_{\mathrm{g}}$ ). As an illustration, Fig. 6 shows the number of lithium disilicate crystals versus nucleation temperature for a fixed nucleation time $t=3 \mathrm{~h}$ (same time used in Ref. [6]) together with the calculated number of crystals which should be nucleated during the

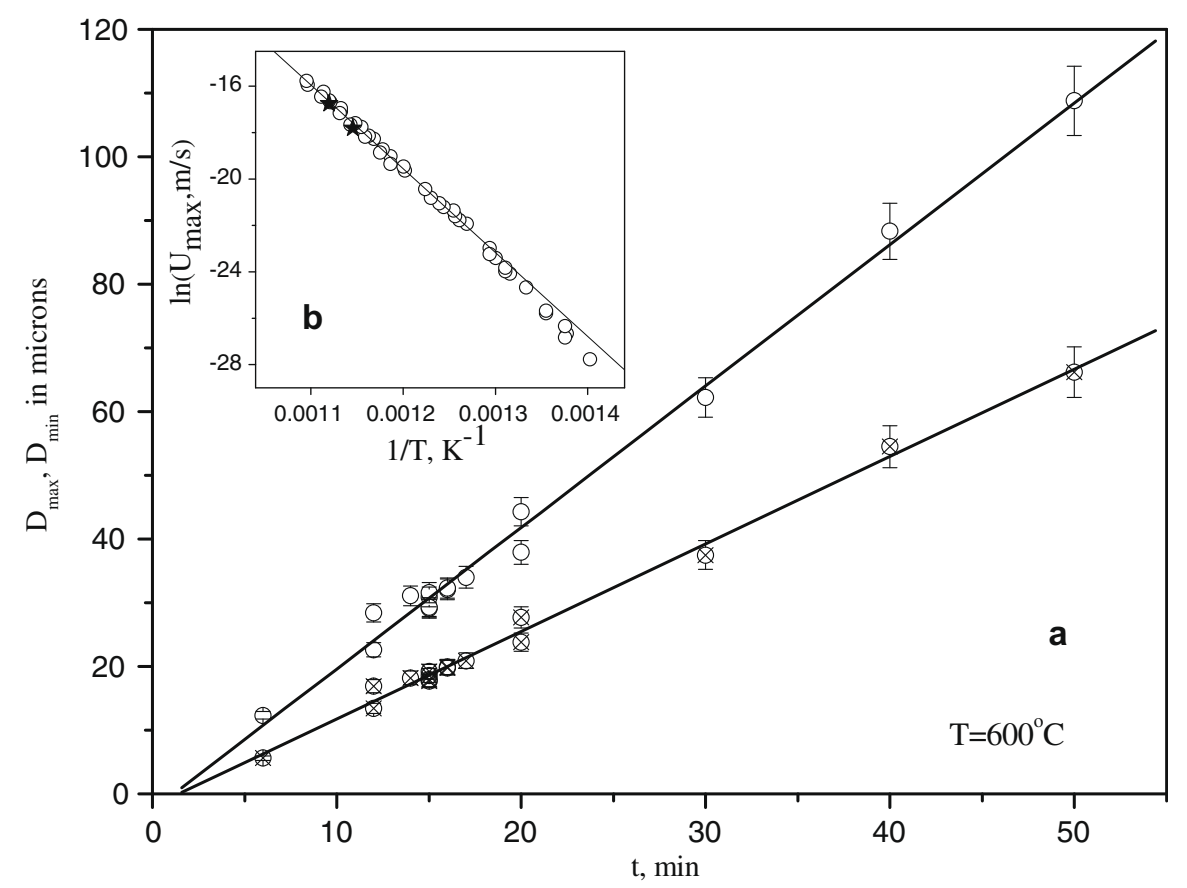

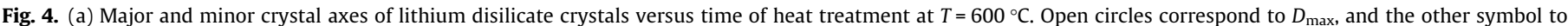

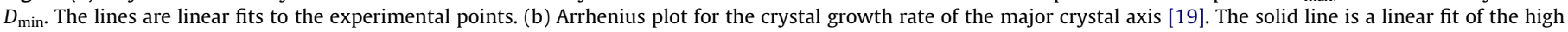
temperature part of the plot. The black stars refer to our own data for the present glass at $T=600{ }^{\circ} \mathrm{C}$ and $620^{\circ} \mathrm{C}$. 


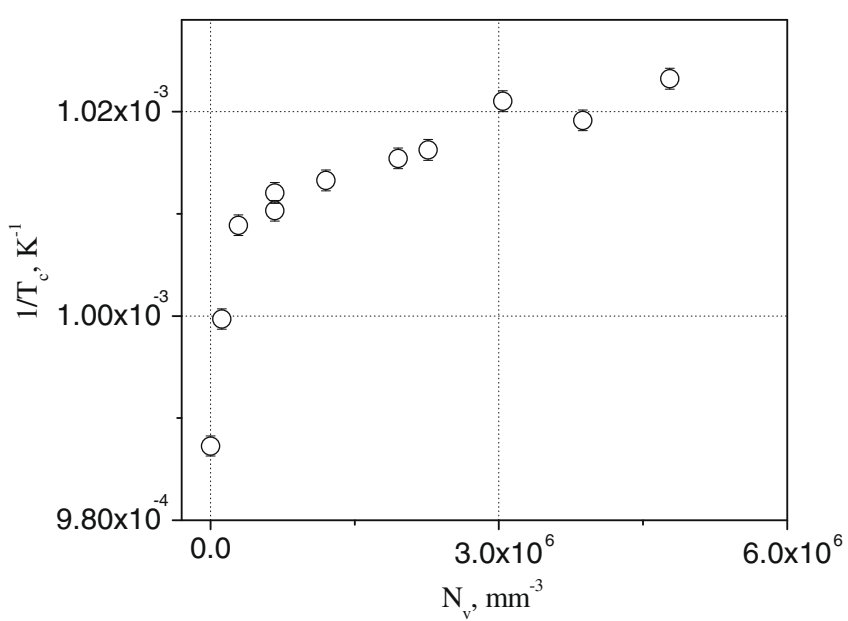

Fig. 5. $1 / T_{\mathrm{c}}$ versus $N$ for a stoichiometric soda-lime-silica glass, $\mathrm{N}_{1} \mathrm{C}_{2} \mathrm{~S}_{3}$.

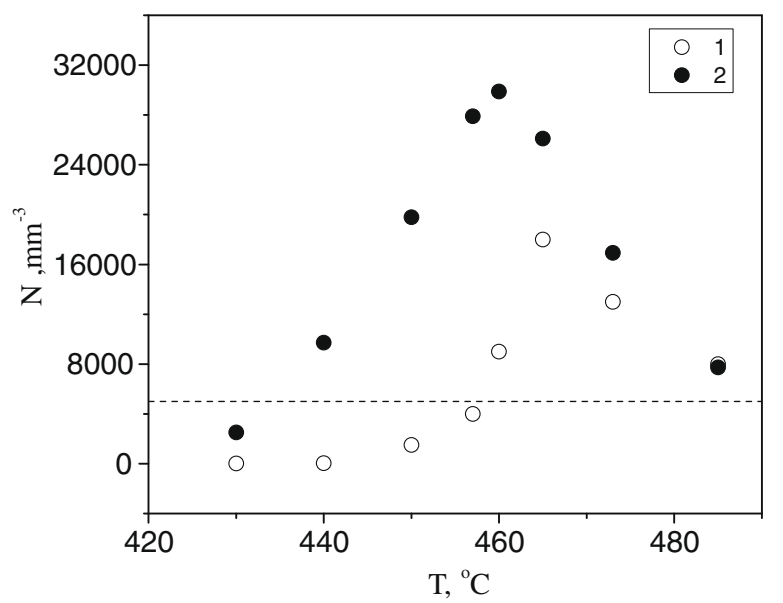

Fig. 6. Number of lithium disilicate crystals $N$ nucleated during $3 \mathrm{~h}$ versus nucleation temperature (1) and calculated for the case of steady-state nucleation (i.e. neglecting time-lag) during the same period of time (2). The dotted line shows the value of $N$ above which the position of the crystallization peak in a DSC curve changes very weakly (see Fig. 3). Plots were obtained using experimental data [20].

same period of time if steady-state nucleation had been achieved. Fig. 7 shows similar plots for $\mathrm{N}_{1} \mathrm{C}_{2} \mathrm{~S}_{3}$ glass. It is clear that due to the time-lag for nucleation, the above method leads to a decrease of the temperature interval of detectable nucleation rate for $\mathrm{L}_{1} \mathrm{~S}_{2}$ glass, and only to a weak decrease for $\mathrm{N}_{1} \mathrm{C}_{2} \mathrm{~S}_{3}$ glass, which at any given temperature has a time-lag lower than those in lithium disilicate glass. However, it is difficult to take into account the effect of time-lag if preliminary nucleation data are not available.

ii. We have shown experimentally and theoretically (see Figs. 3 and 5 ) that the dependence of $1 / T_{\mathrm{c}}$ on crystal number density is close to logarithmic. This means that the sensitivity of the method depends on $N$, i.e. the temperature shift of the crystallization peak for low values of $N$ is much stronger than for high values of $N$. For $\mathrm{L}_{1} \mathrm{~S}_{2}$ glass the change of sensitivity occurs at $N$ about $5000 \mathrm{~mm}^{-3}$ (marked by the doted line in Fig. 6). Since the method implicates a constant nucleation time, $t_{\mathrm{N}}, N$ depends on the nucleation temperature (see Figs. 6 and 7). Hence, if the values of $N\left(T_{\mathrm{N}}\right.$ ) belong to different parts of the $1 / T_{\mathrm{c}}$ versus $N$ plot, the shift of the crystallization peak temperature would be stronger for temperatures below and above the maximum nucleation

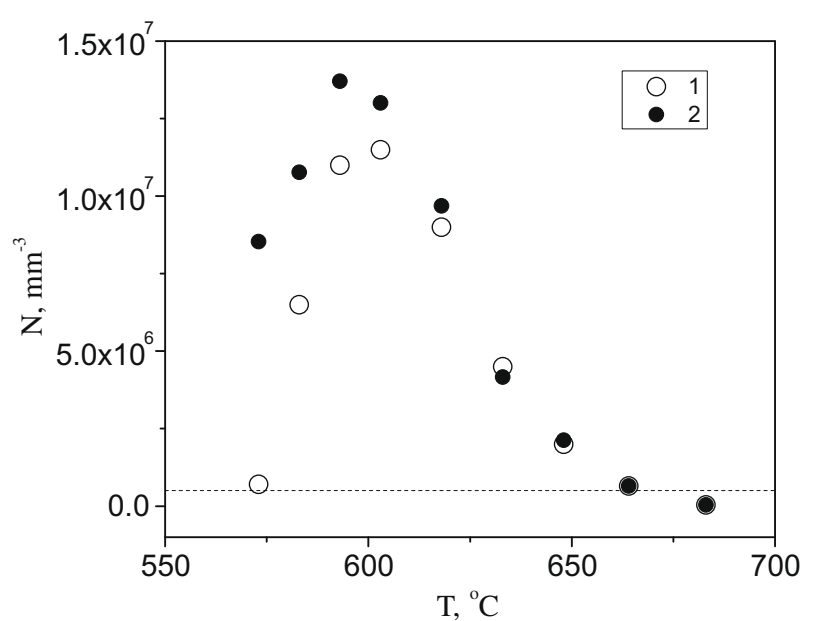

Fig. 7. Number of crystals $N$ nucleated in $\mathrm{N}_{1} \mathrm{C}_{2} \mathrm{~S}_{3}$ glass during $3 \mathrm{~h}$ versus temperature of nucleation (1) and calculated for the case of steady-state nucleation (i.e. neglecting time-lag) during the same period of time (2). The dotted line shows the value of $N$ above which the position of the crystallization peak in a DSC curve changes very weakly (see Fig. 5). Plots were obtained using experimental data [21]

rate than that corresponding to the temperatures of maximum. This is the case of $\mathrm{L}_{1} \mathrm{~S}_{2}$ glass (Fig. 6), while for $\mathrm{N}_{1} \mathrm{C}_{2} \mathrm{~S}_{3}$ glass all values of $N\left(T_{\mathrm{N}}\right)$ belong to the same part of $1 / T_{\mathrm{c}}$ versus $N$ plot (see Fig. 7 ). Thus the logarithmic dependence of $1 / T_{\mathrm{c}}$ on $N$ can alter the shape of the temperature dependence of the nucleation rate. Hence, similarly to the case discussed in the previous paragraph, to take into account the non-linear dependence of $1 / T_{\mathrm{c}}$ on $N$ some nucleation data for the glass under study are required.

\section{Quenched-in and athermic nuclei}

As we have noted, the method elaborated by Ray et al. [7] to estimate the number of nucleated crystals yields the total number of nuclei (not only formed at given nucleation temperature $N\left(T_{\mathrm{N}}\right)$, but also the nuclei formed at non-isothermic and not always controlled regime denoted 'athermic' nuclei, $N_{\mathrm{at}}$ ). To estimate $N_{\mathrm{at}}$ independently on the method suggested in Ref. [7] that will be applied in Section 6, we simulated DSC runs with different heating rates in an electrical furnace. Samples of $\mathrm{L}_{1} \mathrm{~S}_{2}$ glass were dropped into a vertical furnace at $T=400{ }^{\circ} \mathrm{C}$, heated with a rate $C$ up to $T_{\mathrm{G}}=600^{\circ} \mathrm{C}$, and then treated at this temperature for $40 \mathrm{~min}$ to allow crystal growth up to a microscope detectable size. Fig. 8 shows $N_{\text {at }}$ versus heating rate $C$. The star refers to a heat treatment performed directly in the DSC furnace with the following schedule: $24^{\circ} \mathrm{C}-5^{\circ} \mathrm{C} / \mathrm{min}-40^{\circ} \mathrm{C}-(5 \mathrm{~min})-20^{\circ} \mathrm{C} / \mathrm{min}-620^{\circ} \mathrm{C}-(20 \mathrm{~min})-$ $20^{\circ} \mathrm{C} / \mathrm{min}-20^{\circ} \mathrm{C}$. A higher value of $\mathrm{C}$ was achieved when the samples dropped into a furnace preliminary stabilized at $T_{\mathrm{G}}=600^{\circ} \mathrm{C}$. A micrograph of this sample is shown in Fig. 9. As one can see (Fig. 8), the dependence of $N_{\mathrm{at}}$ on $C$ is not linear, as could be expected in the case of steady-state nucleation. The effect of non-steady-state nucleation is more pronounced at high values of $C$. In this case the time spent by the sample during the passage through the temperature range corresponding to the non-steady-state nucleation is lower than the induction period for nucleation.

One can distinguish two kinds of lithium disilicate crystal morphology. One of them is an ellipsoid of revolution observed in Fig. 10, in front (2) and plan (1) views. The other form is spherulitic (Figs. 9 and 10(3)). It should be noted that the spherulite diameters are close to the maximal diameters of the ellipsoids (Fig. 10). The number density of spherulitic crystals is extremely low (about 


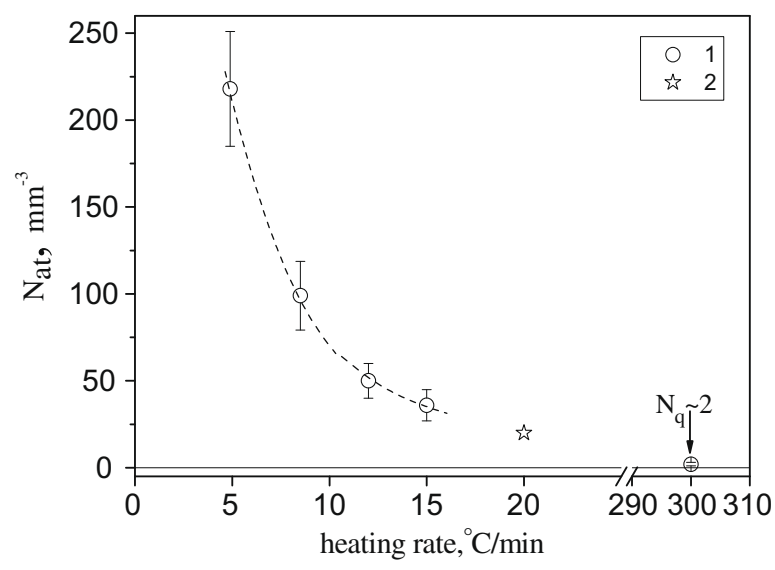

Fig. 8. Number density of a thermal lithium disilicate crystal versus heating rate. Heat treatments were performed in a vertical electrical furnace (1) and in the DSC furnace (2).

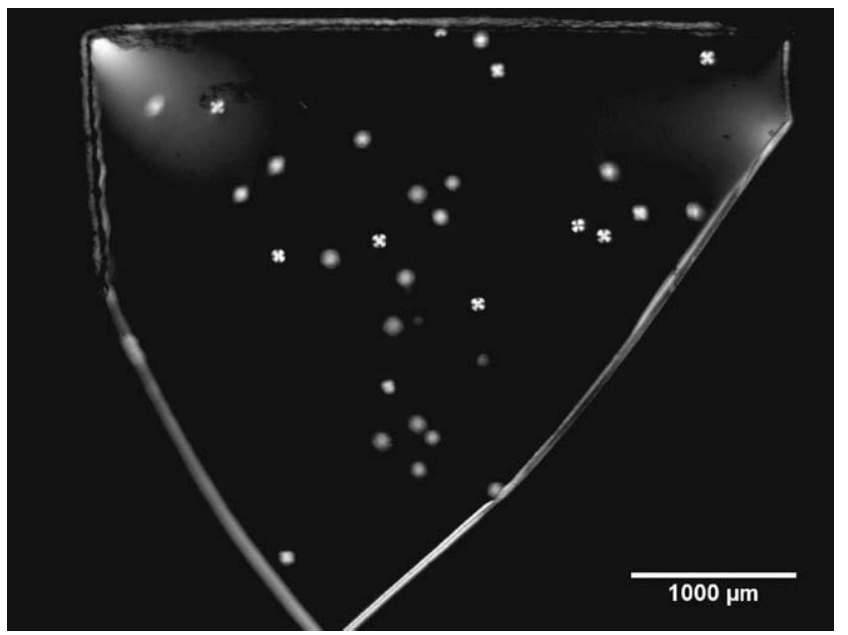

Fig. 9. Micrograph (transmitted polarized light) of a $\mathrm{L}_{1} \mathrm{~S}_{2}$ glass sample treated at $T_{\mathrm{G}}=600{ }^{\circ} \mathrm{C}$ during $40 \mathrm{~min}$ (the heating rate from 20 to $600{ }^{\circ} \mathrm{C}$ was about $300{ }^{\circ} \mathrm{C} /$ $\mathrm{min})$. The sample was a plane-parallel plate of $1.4 \mathrm{~mm}$ thickness.

$2 \mathrm{~mm}^{-3}$ ) and does not depend on the heating rate $C$. This is why we suppose that these spherulitic crystals nucleated on the cooling path during glass preparation and were grown at $T_{\mathrm{G}}=600^{\circ} \mathrm{C}$. In other words, these are quenched-in, 'athermic' crystals. Differently from the quenched-in crystals, those formed via double-stage heat treatment at nucleation and growth temperatures, or nucleated during relative low heating or cooling rates (i.e. crystals having some period of time for growth at the nucleation temperature) have a prolate ellipsoidal shape (see e.g. Fig. 10). According to the experimental data shown in Fig. 8, the number of athermic crystals nucleated during heating with $20^{\circ} \mathrm{C} / \mathrm{min}$ up to $T_{\mathrm{G}}=620^{\circ} \mathrm{C}$ is about $20 \mathrm{~mm}^{-3}$. This value is smaller than that estimated in Ref. [7] by the DTA method by a factor of 450 . Overestimation of $N_{\text {at }}$ results in an error of estimation of $N$ (crystals nucleated at $T_{\mathrm{N}}$ ) and of the nucleation time-lag. One should also recall that the DTA (DSC) method in its original version [7] does not take into account surface crystallization de facto attributing the decrease in the crystallization peak area only to the previously induced volume crystallization and a crushed glass powder was used in [7].

The following section deals with the ratio between volume and surface crystallization.
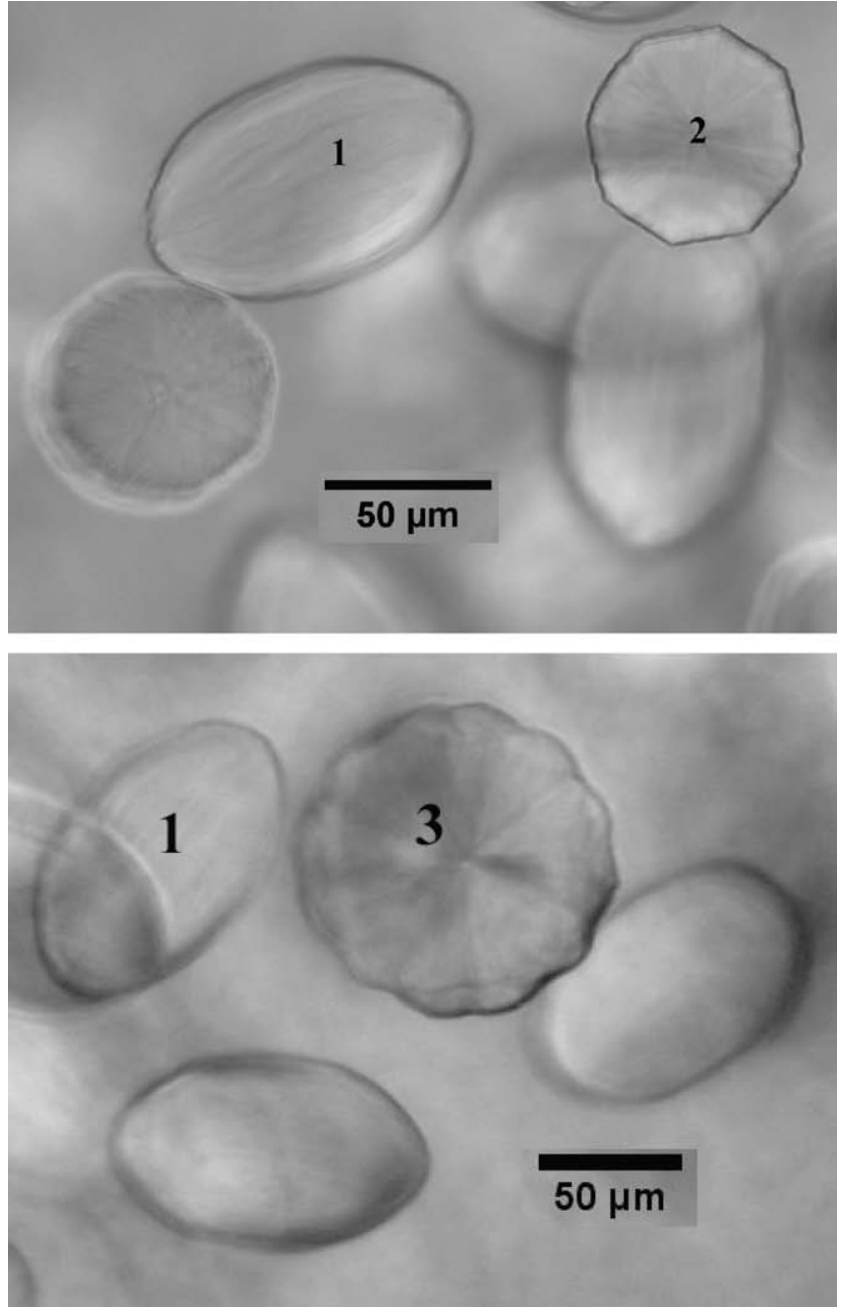

Fig. 10. Micrographs (transmitted light) of lithium disilicate crystals in $\mathrm{L}_{1} \mathrm{~S}_{2}$ glass after heating with $C=10^{\circ} \mathrm{C} / \mathrm{min}$ up to $T_{\mathrm{G}}=600^{\circ} \mathrm{C}$ and holding at this temperature during $40 \mathrm{~min}$. Ellipsoids of revolution in plan (1) and front (2) views, and spherulitic (3) lithium disilicate crystals can be observed.

\section{Surface and internal crystallization}

It is often assumed that if one uses large glass samples it is possible to neglect surface crystallization for analyses of overall crystallization kinetics. For instance, Ray and Day stated $[22,23]$ that internal crystallization in $\mathrm{L}_{1} \mathrm{~S}_{2}$ glass dominates over surface crystallization when the glass particle size exceeds $\sim 300 \mu \mathrm{m}$. However, it is clear that the ratio between internal and surface crystallized fractions also depends on the magnitude of the internal nucleation rates [24]. For instance, in the extreme case when a glass does not undergo internal nucleation or when it is very weak, surface crystallization dominates for all particle sizes. Thus the above characteristic size is a relative quantity that also depends on the time and temperature of crystallization. We carried out heat treatments of a glass powder similar to that used in the DTA run performed in Ref. [7] to estimate $N_{\text {at }}$ by optical microscopy. The $\mathrm{L}_{1} \mathrm{~S}_{2}$ glass powder with size of $400-500 \mu \mathrm{m}$ was heat treated in the DSC furnace at the following schedule: $24^{\circ} \mathrm{C}-5^{\circ} \mathrm{C} / \mathrm{min}-40^{\circ} \mathrm{C}$ $(10 \mathrm{~min})-20^{\circ} \mathrm{C} / \mathrm{min}-600^{\circ} \mathrm{C}-(20 \mathrm{~min})-20^{\circ} \mathrm{C} / \mathrm{min}-24^{\circ} \mathrm{C}$. Fig. 11 shows photos of the glass particles subjected to the above heat treatment. It should be noted that the fine structure refers to the morphology of the thin crystallized surface layer. Only a few isolated crystals are observed in the particle's interior. Due to the irregular form of the particles it is difficult to quantitatively 

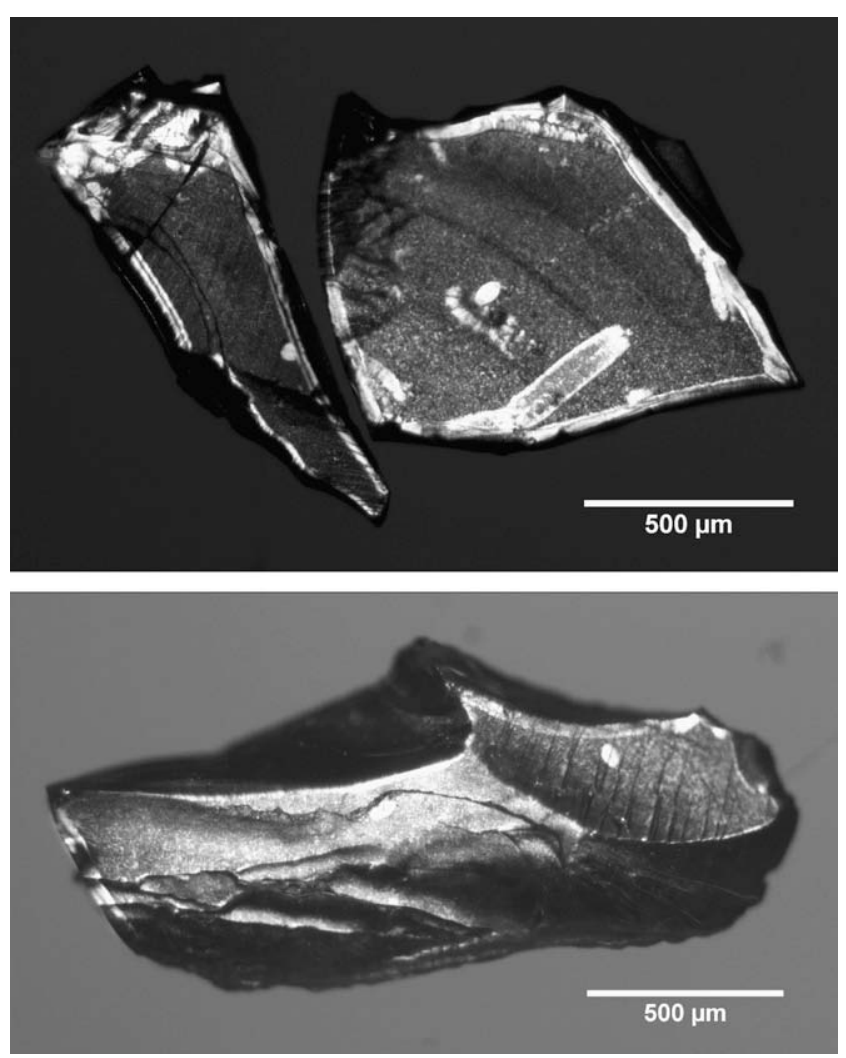

Fig. 11. Photos in transmitted light of $\mathrm{L}_{1} \mathrm{~S}_{2}$ glass particles after treatment performed in the DSC furnace (see text).

estimate the ratio between the fractions of the surface and volume crystals. However, it is obvious that the volume of crystals inside the particles is lower than that of the crystals growing from the surface. For numerical comparison of fractions of surface to volume crystallization we performed DSC run $\left(24^{\circ} \mathrm{C}-5^{\circ} \mathrm{C} / \mathrm{min}-40^{\circ} \mathrm{C}\right.$ $\left.(10 \mathrm{~min})-20^{\circ} \mathrm{C} / \mathrm{min}-620^{\circ} \mathrm{C}-(15 \mathrm{~min})-24^{\circ} \mathrm{C} / \mathrm{min}-20^{\circ} \mathrm{C}\right)$ of a $\mathrm{L}_{1} \mathrm{~S}_{2}$ glass sample with regular form $\left(2.9 \times 2.9 \times 2.1 \mathrm{~mm}^{3}\right)$. An analysis of this sample by optical microscopy shows that only about $20 \%$ of the total crystalline phase corresponds to volume crystallization of athermic crystals. This means that by neglecting surface crystallization one attributes it to crystals nucleated in the sample interior and hence overestimates the number density of the latter. This effect is more pronounced when the crystal number density is low and the sample is small, as e.g. in the case of athermic crystals in a glass powder. Obviously the contribution of internal crystallization increases when the glass sample is subjected to a preliminary nucleation heat treatment. Such the sample of $\mathrm{L}_{1} \mathrm{~S}_{2}$ glass with sizes $3.4 \times 3.5 \times 1.3 \mathrm{~mm}^{3}$ after DSC run including a nucleation step $\left(24{ }^{\circ} \mathrm{C}-5{ }^{\circ} \mathrm{C} / \mathrm{min}-40^{\circ} \mathrm{C}-(10 \mathrm{~min})-20^{\circ} \mathrm{C} / \mathrm{min}-\right.$ $480^{\circ} \mathrm{C}-(30 \mathrm{~min})-20^{\circ} \mathrm{C} / \mathrm{min}-620^{\circ} \mathrm{C}-(10 \mathrm{~min})-20^{\circ} \mathrm{C} / \mathrm{min}-$ $24^{\circ} \mathrm{C}$ ) revealed a ratio between surface and volume fractions of crystalline phase about $1: 3.3$.

In the Section 6, we will present an estimate of the crystal number density, including the number of athermic nuclei, by the DSC method of Ray et al. [7] taking into account the effect of surface crystallization.

\section{Estimate of the crystal number density in $L_{1} S_{2}$ glass by the DSC method of Ray et al.}

To estimate the number of nucleated crystals we employed the following general form of Eq. (2) not using the serial expansion of exponent in JMAYK equation, as it was done in Ref. [7].

$$
\frac{A_{1}}{A_{2}}=\frac{\exp \left(-\frac{4 \pi}{3} N \frac{U_{\max }^{3}}{K^{2}} t_{\mathrm{G} 1}^{3}\right)}{\exp \left(-\frac{4 \pi}{3} N \frac{U_{\max }^{3}}{K^{2}} t_{\mathrm{G} 2}^{3}\right)}
$$

One should recall that $N$ is the number of crystals preliminary nucleated at $T_{\mathrm{N}}$ and then grown at $T_{\mathrm{G}}$ during $t_{\mathrm{G}}$. Here we neglected the athermic nuclei whose number is very low as it was already shown by direct measurements (see Sections 4 and 5) and will be estimated by the DSC method later. According to Eq. (6) $U$ was replaced by $U_{\max }$. Also, since $A_{1}$ and $A_{2}$ are the crystallization peak areas per unit mass of samples, we do not use the terms $M_{1}$ and $M_{2}$ (see Eq. (2)). In the next step, we introduce corrections in Eq. (10) that take into account the decreased glassy part of the sample due to surface crystallization.

$\frac{A_{1}}{A_{2}}=\frac{\exp \left(-\frac{4 \pi}{3} N \frac{U_{\max }^{3}}{K^{2}} t_{\mathrm{G} 1}^{3}\right) \beta_{1}}{\exp \left(-\frac{4 \pi}{3} N \frac{U_{\max }^{3}}{K^{2}} t_{\mathrm{G} 2}^{3}\right) \beta_{2}}$.

Here $\beta$ is the ratio between the sample volume reduced due to surface crystallization, $V_{\text {red }}$, and the initial sample volume $V$. Introducing $\beta$ we consider that the volume of residual glass responsible for the crystallization peak on the DSC curve decreases due to both surface and volume crystallization. From Eq. (11) we obtain the following equation for $N$.

$N=\frac{3}{4 \pi} \frac{K^{2}}{U_{\max }^{3}} \ln \left[\frac{A_{1} \beta_{2}}{A_{2} \beta_{1}}\right] \frac{1}{t_{\mathrm{G} 2}^{3}-t_{\mathrm{G} 1}^{3}}$.

To best reproduce the conditions of DSC analysis and to facilitate the estimation of the coefficient $\beta$ we prepared samples of regular shape with sizes $a=2.9, b=2.9$, and $c=2.1 \mathrm{~mm}$, whose weight varied from 39 to $41 \mathrm{mg}$. The coefficient $\beta$ was estimated as

$\beta=\frac{(a-2 h)(b-2 h)(c-2 h)}{a b c}$,

where $h$ is the thickness of crystalline layer after heat treatment at $T_{\mathrm{G}}$.

It should be emphasized that according to Eq. (12), which can be rewritten as

$N=\frac{3}{4 \pi} \frac{K^{2}}{U_{\max }^{3}} \ln \left[\frac{A_{1}}{A_{2}}\right] \frac{1}{t_{\mathrm{G} 2}^{3}-t_{\mathrm{G} 1}^{3}}+\frac{3}{4 \pi} \frac{K^{2}}{U_{\max }^{3}} \ln \left[\frac{\beta_{2}}{\beta_{1}}\right] \frac{1}{t_{\mathrm{G} 2}^{3}-t_{\mathrm{G} 1}^{3}}$,

at constant $t_{\mathrm{G} 1}, t_{\mathrm{G} 2}$ and sample shape, the correction by surface crystallization leads to a decrease in $N$ by a given amount that does not depend on the crystal number density (see Fig. 15 points 2 and 3 for $t_{\mathrm{N}}=10,20$, and $30 \mathrm{~min}$ ). This result means that at the above condition this correction does not change the slope of the $N\left(t_{\mathrm{N}}\right)$ plot and only changes the absolute values of $N$ and time-lag (or induction period) for nucleation.

It is usually assumed that using fairly high heating and cooling rates (e.g. $20^{\circ} \mathrm{C} / \mathrm{min}$ ) one can neglect crystal growth during the non-isothermal regime. However, for short growth times, this assumption may not be valid. Also, some overheat may take place during the growth stage. Both effects lead to an underestimate of the effective growth rate and hence lead to an increase in the values of $N$ (see Eq. (12)). We have checked this hypothesis by using Eq. (15) a slightly altered version of Eq. (12). This equation considers the actual crystal sizes $r_{1}$ and $r_{2}$ after the nucleation and growth steps hereby taking into account non-isothermal growth.

$N=\frac{3}{4 \pi} K^{2} \ln \left[\frac{A_{1} \beta_{2}}{A_{2} \beta_{1}}\right] \frac{1}{r_{2}^{3}-r_{1}^{3}}$

Three nucleation times $\left(t_{\mathrm{N}}=10,20\right.$, and $\left.30 \mathrm{~min}\right)$ at $T_{\mathrm{N}}=480^{\circ} \mathrm{C}$ were used. The samples were subjected to the following DSC run: $24{ }^{\circ} \mathrm{C}-5{ }^{\circ} \mathrm{C} / \mathrm{min}-40{ }^{\circ} \mathrm{C}-(5 \mathrm{~min})-20^{\circ} \mathrm{C} / \mathrm{min}-480{ }^{\circ} \mathrm{C}-\left(t_{\mathrm{N}}\right)-$ $20^{\circ} \mathrm{C} / \mathrm{min}-620^{\circ} \mathrm{C}-\left(t_{\mathrm{G}}\right)-20^{\circ} \mathrm{C} / \mathrm{min}-300^{\circ} \mathrm{C}-(5 \mathrm{~min})-10^{\circ} \mathrm{C} / \mathrm{min}$ 
$-800{ }^{\circ} \mathrm{C}-20^{\circ} \mathrm{C} / \mathrm{min}-24^{\circ} \mathrm{C}$, with $t_{\mathrm{G}}=10$ and $15 \mathrm{~min}$. Some examples of these DSC curves together with the temperature schedule are shown in Fig. 12. To measure the crystal growth rate at $T_{\mathrm{G}}=620^{\circ} \mathrm{C}$ five samples were prepared for optical measurement via DSC runs: $24^{\circ} \mathrm{C}-5{ }^{\circ} \mathrm{C} / \mathrm{min}-40^{\circ} \mathrm{C}-(5 \mathrm{~min})-20^{\circ} \mathrm{C} / \mathrm{min}-$ $480{ }^{\circ} \mathrm{C}-(10 \mathrm{~min})-20^{\circ} \mathrm{C} / \mathrm{min}-620^{\circ} \mathrm{C}-\left(t_{G}\right)-20^{\circ} \mathrm{C} / \mathrm{min}-24^{\circ} \mathrm{C}$ with $t_{\mathrm{G}}=0,5,10,15$, and $20 \mathrm{~min}$. The values of the maximal and minimal diameters of ellipsoidal $\mathrm{L}_{1} \mathrm{~S}_{2}$ crystals are shown in Fig. 13 versus growth time $t_{\mathrm{G}}$. According to this plot, $U_{\max }=5.31 \times 10^{-8} \mathrm{~m} / \mathrm{s}$ and $K=1.623$. As we already noted, this value agrees with the literature data shown in the inset of Fig. 4 . To estimate the number of athermic nuclei some samples were subjected to the following DSC runs: $24^{\circ} \mathrm{C}-5{ }^{\circ} \mathrm{C} / \mathrm{min}-40{ }^{\circ} \mathrm{C}-(5 \mathrm{~min})-20^{\circ} \mathrm{C} / \mathrm{min}-620^{\circ} \mathrm{C}-\left(t_{\mathrm{G}}\right)-$ $20^{\circ} \mathrm{C} / \mathrm{min}-300^{\circ} \mathrm{C}-(5 \mathrm{~min})-10^{\circ} \mathrm{C} / \mathrm{min}-800{ }^{\circ} \mathrm{C}-20^{\circ} \mathrm{C} / \mathrm{min}-$ $24^{\circ} \mathrm{C}$ with $t_{\mathrm{G}}=25$ and $40 \mathrm{~min}$, that as opposed to the full DSC runs, does not include the nucleation treatment. The conditions and results of the DSC analysis together with data from optical measurements of samples subjected to DSC runs without the last stage of full crystallization are presented on Table 2. A photo of one sample is shown in Fig. 14.

Fig. 15 presents the number of nucleated crystals estimated by the DSC method corrected for surface crystallization (Eq. (12)), accounting for non-isothermal growth (Eq. (15)) and without such corrections (Eq. (10)), together with optical measurements. In general the values of $N$ (including $N_{\mathrm{at}}$ ) estimated by DSC method are close to those measured by optical microscopy (see also Table 2 ).

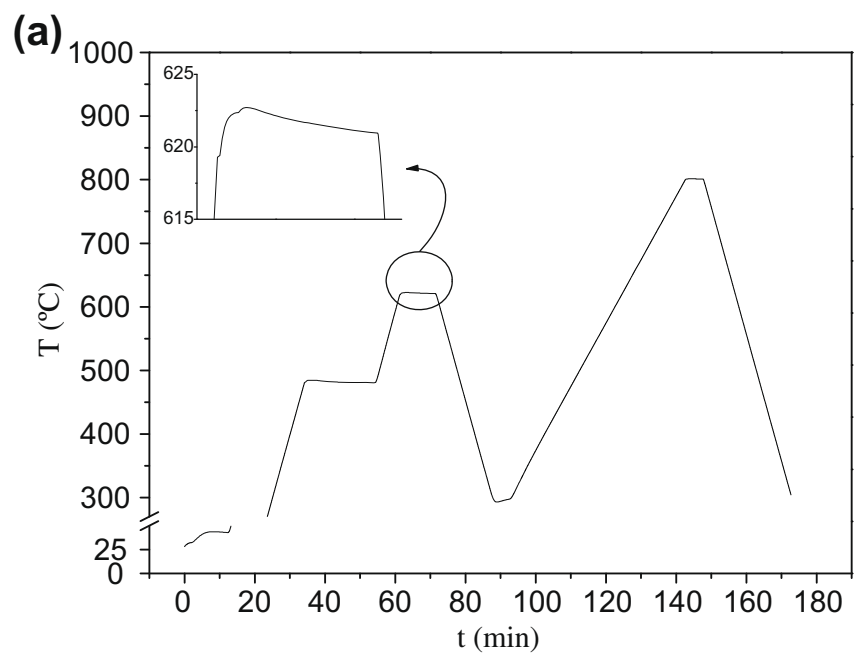

(b)

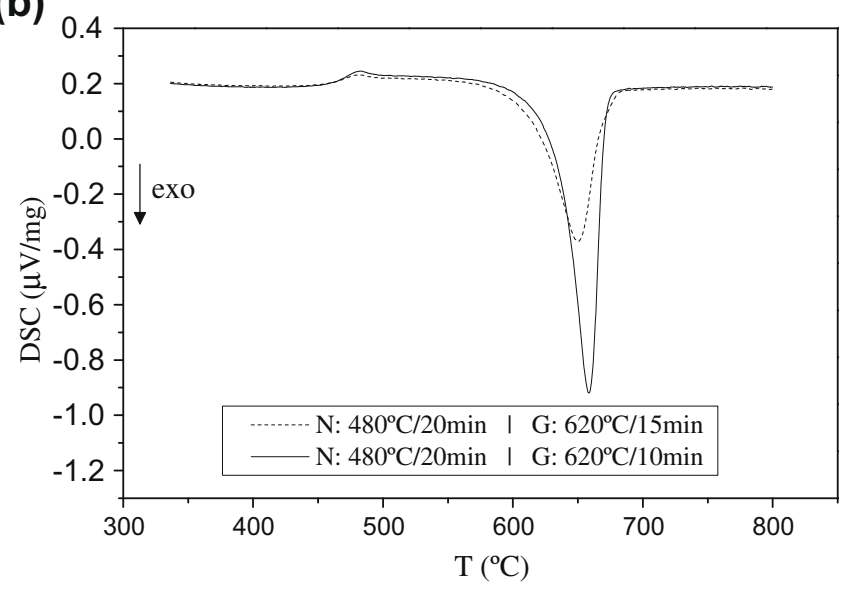

Fig. 12. The DSC curves for the samples of $\mathrm{L}_{1} \mathrm{~S}_{2}$ glass treated for nucleation at $480{ }^{\circ} \mathrm{C}$ for $20 \mathrm{~min}$. (a) DSC schedule and overshooting during growth (detail). (b) Crystallization peaks after nucleation and growth.

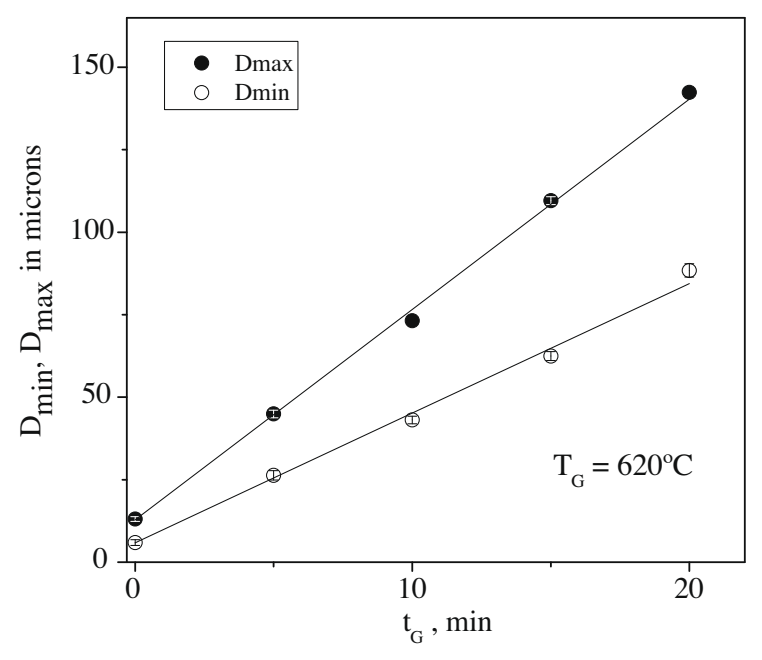

Fig. 13. Major and minor crystal diameters of lithium disilicate crystals versus time of heat treatment at $T=620^{\circ} \mathrm{C}$. The lines are linear fits to the experimental points. The samples were heat treated in the DSC (see text).

However, the values of $N$ estimated via DSC neglecting non-isothermal growth are systematically higher than those measured by optical microscopy. It is important to note that unlike the correction by surface crystallization, an account for non-isothermal growth leads to a decrease of the slope of the $N\left(t_{\mathrm{N}}\right)$ plot. The values of $N$ corrected for surface crystallization and considering non-isothermal growth (Eq. (15)) approached the ones directly estimated by optical microscopy. This result shows that for short growth times, the assumption that the heating and cooling steps are negligible compared to isothermal growth is not correct. To minimize this influence, one can use longer isothermal times; however $t_{\mathrm{G}}$ is limited by the time of total crystallization of the sample at $T_{\mathrm{G}}$.

Finally, it should be emphasized that the above described methods are quite time-consuming. One full DSC run (for short nucleation time) needs about $3 \mathrm{~h}$. One has to perform two DSC runs to estimate a single value of $N$. Additionally, in order to choose the correct values of $t_{\mathrm{G}}$ one needs to have some idea about the nucleation rate, if not the change of the crystallization peak area would be too strong or too weak. Moreover, one has to know the value of the crystal growth rate at $T_{\mathrm{G}}$ and the crystal shape. Finally, the preparation of bulk samples is quite laborious compared to preparation of a powder, but the use of powders results in important and unaccountable errors caused by surface crystallization.

\section{On the area of exothermic DTA/DSC crystallization peaks}

The method of Ray et al. [7] to estimate the number of nucleated crystals, previously described and applied, is based on the reasonable assumption that the area of a DTA (DSC) crystallization peak is proportional to the mass of crystallized glass. This assumption is correct if the change of sensitivity of the method with temperature is neglected. Thus one can expect that the area of the crystallization peak of the glass samples with the same mass or reduced per unit mass does not depend on the number density of the preliminary nucleated crystals. The temperature and time of the nucleation heat treatment must be chosen in such way that the volume of nuclei can be neglected. This condition was fulfilled for the data presented in Fig. 16. Indeed the variation of $A$ with the number of crystals for $\mathrm{L}_{1} \mathrm{~S}_{2}$ glass is within the error limits (Fig. 16(a)), while in the case of $\mathrm{N}_{1} \mathrm{C}_{2} \mathrm{~S}_{3}$ glass (Fig. 16(b)) a weak but well defined decrease of $A$ takes place as the number of crystals increases. Note again that the volume of previously formed nuclei 
Table 2

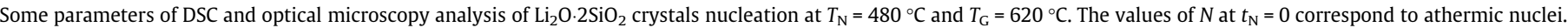

\begin{tabular}{|c|c|c|c|c|c|c|c|c|c|}
\hline$t_{\mathrm{N}}(\min )$ & $t_{\mathrm{G}}(\min )$ & $A_{1}(\mu \mathrm{Vs} / \mathrm{mg})$ & $A_{2}(\mu \mathrm{Vs} / \mathrm{mg})$ & $\beta_{1}$ & $\beta_{2}$ & $N$ (Eq. (10), $\mathrm{m}^{-3}$ ) & $N$ (Eq. (12), $\left.\mathrm{m}^{-3}\right)$ & $N$ (Eq. (15), $\mathrm{m}^{-3}$ ) & $N$ [optic] $\left(\mathrm{m}^{-3}\right)$ \\
\hline 0 & 25 & 181.4 & & 0.768 & & $1.31 \times 10^{11}$ & $6.20 \times 10^{10}$ & - & $1.90 \times 10^{10}$ \\
\hline 0 & 40 & & 131 & & 0.647 & & & & \\
\hline 10 & 10 & 204.9 & & 0.904 & & $1.30 \times 10^{12}$ & $8.55 \times 10^{11}$ & $5.70 \times 10^{11}$ & $7.31 \times 10^{11}$ \\
\hline 10 & 15 & & 174.7 & & 0.855 & & & & \\
\hline 20 & 10 & 187.5 & & 0.903 & & $2.59 \times 10^{12}$ & $2.15 \times 10^{11}$ & $1.43 \times 10^{12}$ & $1.39 \times 10^{12}$ \\
\hline 20 & 15 & & 136.5 & & 0.856 & & & & \\
\hline 30 & 10 & 173.7 & & 0.902 & & $4.92 \times 10^{12}$ & $4.49 \times 10^{11}$ & $2.99 \times 10^{12}$ & $2.35 \times 10^{12}$ \\
\hline 30 & 15 & & 95.1 & & 0.856 & & & & \\
\hline
\end{tabular}

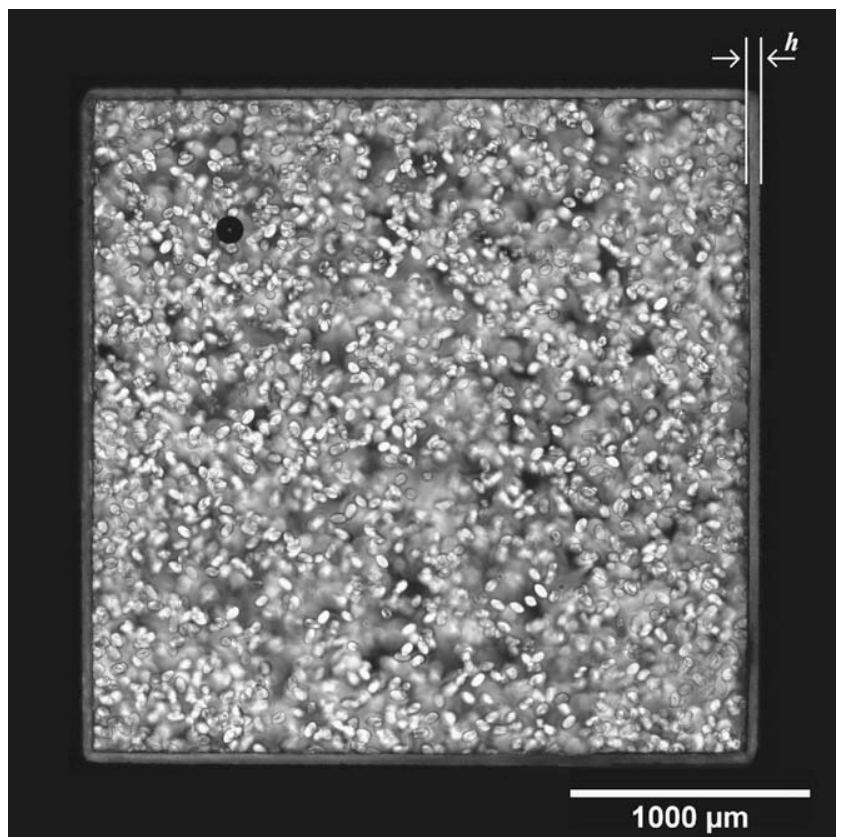

Fig. 14. Transmitted light micrograph of a $\mathrm{L}_{1} \mathrm{~S}_{2}$ glass sample after following DSC run: $24^{\circ} \mathrm{C}-5^{\circ} \mathrm{C} / \mathrm{min}-40^{\circ} \mathrm{C}-(5 \mathrm{~min})-20^{\circ} \mathrm{C} / \mathrm{min}-480^{\circ} \mathrm{C}-(10 \mathrm{~min})-20^{\circ} \mathrm{C} / \mathrm{min}-$ $620^{\circ} \mathrm{C}-(10 \mathrm{~min})-20^{\circ} \mathrm{C} / \mathrm{min}-24^{\circ} \mathrm{C}$.

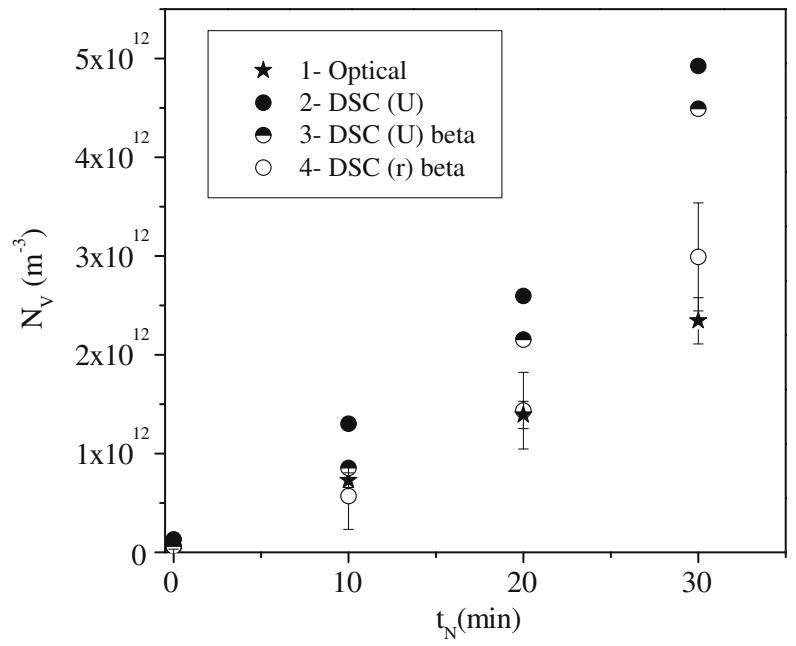

Fig. 15. Crystal number density in $\mathrm{L}_{1} \mathrm{~S}_{2}$ glass versus time of nucleation at $T_{\mathrm{N}}=480^{\circ} \mathrm{C}$ obtained by different methods: 1 - optical microscopy, 2 - DSC method by Eq. (10), 3 - Eq. (12) and 4 - Eq. (15).

did not exceed $0.05 \%$. The observed effect cannot be explained by the change of the sensitivity of method with temperature since
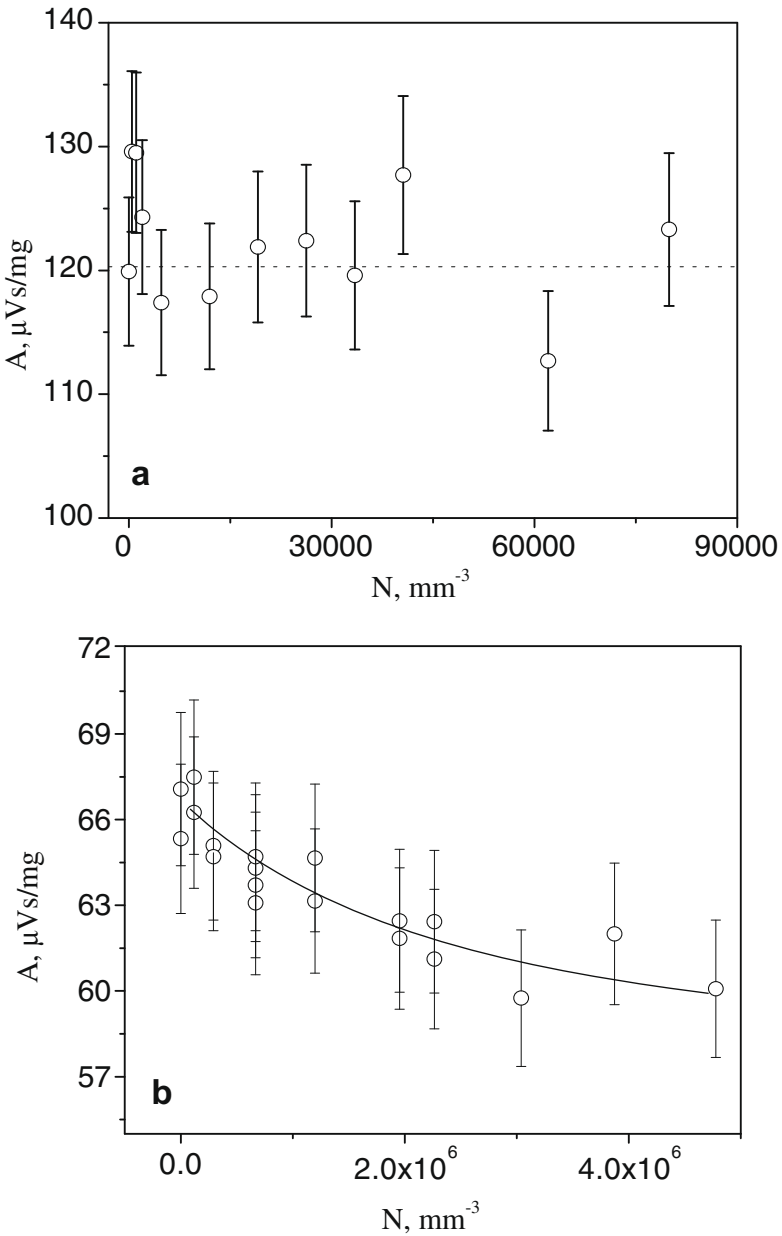

Fig. 16. Area of the crystallization peak versus number of crystals for $\mathrm{L}_{1} \mathrm{~S}_{2}$ (a) and $\mathrm{N}_{1} \mathrm{C}_{2} \mathrm{~S}_{3}$ (b) silicate glasses.

an increase of $N$ results in a decrease of $T_{\mathrm{c}}$ (see Fig. 5), while the sensitivity increases with decreasing temperature. This means that despite reaching $100 \%$ crystallinity this particular system still does not achieve equilibrium. The degree of non-equilibrium is higher when the number of crystals is larger, i.e. the system has a finer structure. Two reasons for the above effect seem possible. The first is the structural and compositional inhomogeneity of the crystallized sample. One should recall that $\mathrm{Na}_{2} \mathrm{O} \cdot 2 \mathrm{CaO} \cdot 3 \mathrm{SiO}_{2}$ crystals form via nucleation of a sodium rich solid solution that during the growth process approaches the stoichiometric composition [25]. The second possibility is elastic stresses that can arise in a polycrystal. We show these dependencies of $A$ on $N$ only to illustrate that the reasonable assumption about the proportionality of mass of glass subjected crystallization to the area of an exothermic DSC peak is not always fulfilled. 


\section{Conclusions}

We tested two DSC/DTA methods against the traditional microscopy method to estimate the temperature range of the nucleation rate maximum and the number of supercritical crystal nuclei.

The dependence of the DSC/DTA crystallization peak position on the number of pre-existing nuclei is not linear. This fact together with non-steady-state nucleation (which is always significant at some temperature range below or just above the glass transition temperature) distorts the real temperature dependence of the nucleation rate when one employs the shift of crystallization peak method.

The ratio between volume and surface crystallization depends not only on sample size, but also on the number density of internal crystals. The role of surface crystallization is more pronounced when the number of crystals in the volume is small, e.g. in the case of athermic crystals. Hence particle size alone is not sufficient to account for the relative importance of surface crystallization. Also, crystal growth in the non-isothermal regime can have a significant effect on the calculated crystal number density and nucleation rates. The area of a DTA/DSC crystallization peak can be affected by the formation of non-equilibrium phases or by elastic stresses. All these factors hinder an accurate analysis of nucleation kinetics by DSC/DTA methods.

Finally, one needs preliminary data on the nucleation and growth rates of the studied glass to take into account all the above effects when employing DTA/DSC methods to determine nucleation kinetics. When properly employed such non-isothermal methods can give useful kinetic information, which includes the crystal number density, but they are as laborious as the traditional microscopy methods.

\section{Acknowledgements}

The authors are indebted to Brazilian agencies CNPq \# 620249/ 2006-4 and 143040/2008-1, Fapesp \# 2007/08179-9, 2008/00475-
0 , and \# 2008/00475-0 for funding this research. We are also thankful to Dr. Chandra Ray for his critical comments.

\section{References}

[1] G. Tammann, Z. Phys. Chem. 25 (1898) 441.

[2] V.M. Fokin, E.D. Zanotto, N.S. Yuritsyn, J.W.P. Schmelzer, J. Non-Cryst. Solids 352 (2006) 2681.

[3] A. Marotta, A. Buri, Thermochim.Acta 25 (1981) 341.

[4] A. Marotta, A. Buri, F. Branda, S. Saiello, Nucleation and crystallization of $\mathrm{Li}_{2} \mathrm{O}_{2} \mathrm{SiO}_{2}$ glass-A DTA study, in: J.H. Simmons, D.R. Uhlman, G.H. Beall (Eds.), Advances in Ceramics, vol.4, Nucleation and Crystallization in Glasses, American Ceramic Society, Columbus, OH, 1982, pp. 146-152.

[5] X.J. Xu, C.S. Ray, D.E. Day, J. Am. Ceram. Soc. 74 (1991) 909.

[6] C.S. Ray, D.E. Day, J. Am. Ceram. Soc. 73 (1990) 439

[7] C.S. Ray, X. Fang, D.E. Day, J. Am. Ceram. Soc. 83 (2000) 865.

[8] K.S. Ranasingne, C.S. Ray, D.E. Day, J. Mater. Sci. 37 (2002) 547

[9] M.C. Weinberg, J. Am. Ceram. Soc. 74 (1991) 1905.

[10] K.F. Kelton, J. Am. Ceram. Soc. 75 (1992) 2449.

[11] C.S. Ray, D.E. Day, J. Am. Ceram. Soc. 80 (1997) 3100.

[12] W.A. Johnson, R.F. Mehl, Trans. A.I.M.E. 135 (1939) 416

[13] M. Avrami, J. Chem. Phys. 7 (1939) 1103 M. Avrami, J. Chem. Phys. 8 (1940) 212 M. Avrami, J. Chem. Phys. 9 (1941) 177.

[14] B.V. Yerofyeyev, Dokl. Akad. Nauk USSR 52 (1946) 511 (in Russian).

[15] A.N. Kolmogorov, Izv. Akad. Nauk USSR (1937) 355 (in Russian).

[16] K.S. Ranasinghe, P.F. Wei, K.F. Kelton, C.S. Ray, D.E. Day, J. Non-Cryst. Solids 337 (2004) 261.

[17] P.C. Soares Jr., E.D. Zanotto, V.M. Fokin, H. Jain, J. Non-Cryst. Solids 331 (2003) 217.

[18] I. Gutzov, J.W. Schmelzer, The Vitreous State: Thermodynamics, Structure, Rheology and Crystallization, Springer, Berlin, 1995.

[19] Siglass data - Science Vision Version 5. www.esm-software-com/vciglass.

[20] V.M. Fokin, PhD thesis, Institute of Silicate Chemistry of Russian Academy Sciences, 1980 (in Russian)

[21] O.V. Potapov, V.M. Fokin, V.L. Ugolkov, L.Y. Suslova, V.N. Filipovich, Glass Phys. Chem. 26 (2000) 27.

[22] C.S. Ray, D.E. Day, Thermochim. Acta 280/281 (1996) 163

[23] C.S. Ray, Q. Yang, W. Huang, D.E. Day, J. Am. Ceram. Soc. 79 (1996) 3155.

[24] N. Koga, J. Šesták, Soc. Esp. Ceram. Vidr. 1 (1992) 185

[25] V.M. Fokin, O.V. Potapov, E.D. Zanotto, F.M. Spiandorello, V.L. Ugolkov, B.Z. Pevzner, J. Non-Cryst. Solids 331 (2003) 240. 